\title{
A subjetividade da CPLP à luz do Direito Internacional Público e 0 impacto da mesma sobre a promoçc̃o dos Direitos Humanos no seio do "Espaço de Cooperação Lusófona"
}

\author{
Alexandra Jesus de Oliveira Lopes
}

Introdução

Pretende-se aqui explorar a potencialidade da CPLP, enquanto organização internacional, na promoção do respeito e efetivação dos Direitos Humanos no âmbito de um espaço de cooperação lusófona, onde a maior parte dos seus membros são países em desenvolvimento.

Desde a sua criaçãa, em julho de 1996, o projeto da CPLP tem em si subjacente um conjunto de desafios que se projetam na sua natureza (enquanto sujeito de direito internacional); no seu funcionamento e, por conseguinte, nas suas concretizações (quer num plano de promoção dos direitos humanos, como também ao nível da cooperação estratégica dos seus Estados-Membros nas mais variadas frentes).

Propõe-se ainda apelar a uma reestruturação do modus operandi da CPLP no sentido de desenvolver políticas verdadeiramente operacionais que possam trazer um impacto efetivo sobre os direitos e liberdades civis e políticas e os direitos económicos, sociais e culturais dos vários Estados-Membros da CPLP. 
ULP Law Review | Revista de Direito da ULP

Vol. 13, n. .9

doi:10.46294/ulplr13n1d4

\section{A Soberania dos Estados-Membros e o seu Impacto no âmbito das Ações da

As ações de cooperação no seio da CPLP, sobretudo com os Países de Língua Oficial Portuguesa (PALOP) e Timor-Leste, deverão ser avaliadas pelo seu impacto na promoção dos direitos civis e políticos (vitais para a consolidação de um Estado de Direito), mas também dos direitos económicos, sociais e culturais.

Tal tarefa, no entanto, deverá ser precedida de uma análise dos textos da CPLP (a Declaração Constitutiva e os Estatutos) para que se possa apurar qual o âmbito da atuação da mesma.

Se observarmos 0 artigo 5\% dos Estatutos da CPLP verificamos que, seguindo a mesma linha a da Declaração Constitutiva, procura-se respeitar a soberania dos EstadosMembros, desde logo assumindo que a atuação da CPLP estará subordinada a um princípio de igualdade soberana dos Estados. Trata-se de uma Associação de Estados afirmando uma personalidade jurídica que nãos e confunde com personalidades jurídicas inerentes a cada um dos Estados-Membros.

Ao contrário do que sucede com uma Federação, em que 0 ordenamentojurídico federal prevalece sobre os respetivos ordenamentos federados, consubstanciando-senum regime hierárquico (nos termos do qual as normas da autoridade central serão sempre superiores às emanadas pelas instâncias federadas), na CPLP a solidariedade tem de ser, por força da normatividade dos Estatutos, de tipo horizontal.

\section{A vocação Universalista da CPLP}

Contudo, "tendo em mente o respeito pela integridade territorial e a não-ingerência 
ULP Law Review | Revista de Direito da ULP

Vol. 13, n. .1

doi: 10.46294/ulplr13n1d4

nos assuntos internos de cada Estado, bem como o direito de cada um estabelecer as formas do seu próprio desenvolvimento político, económico e social e adotar soberanamente as respetivas políticas e mecanismos nesses domínios"1] a CPLP visa simultaneamente promover o respeito pelos direitos humanos nos respetivos Estados.

Efetivamente, se olharmos para a declaração constitutiva da CPLP verifica-se que à ideia de cooperação está subjacente o desenvolvimento económico e social dos seus Povos. Não existindo uma prevalência económica tão marcante como habitualmente existe noutros mecanismos de cooperação internacional, o enfoque está na erradicação da pobreza, no desenvolvimento sustentado e na concretização do Estado de Direito por meio da dinamização de ações de peace-building.

Não obstante, sem querer afirmar que estamos perante realidades totalmente incompatíveis, também é igualmente importante fazer notar a existência de uma certa postura ilusória desta comunidade cujas aspirações se deixam comprometer por esta ênfase tão marcada na intergovernamentalidade.

Esta última característica é, desde logo, indissociável da própria dinâmicainterna de funcionamento da CPLP. Tomem-se como exemplo as Reuniões Ministeriais Sectoriais. As mesmas cristalizam uma mera concertação de interesses sem prejuízo de o desenvolvimento das políticas sectoriais ser efetivado no plano ministerial de cada um dos Estados-Membros.

Sem embargo de a CPLP assentar num princípio de respeito pela soberania dos Estados, o facto de a comunidade se focar igualmente em valores universais associados à Dignidade da Pessoa Humana leva-nos a questionar como se pode ultrapassar esta aparente contradição lógica.

Para tal, no entanto, importa explicar, antes de mais, o que é que está na génese desta "atitude protetora" e, por outro, entender por que razão, haveria que flexibilizar uma mudança de paradigma no sentido de promover uma atuação mais efetiva da CPLP.

' Cf. Declaraçãõo Constitutiva da Comunidade de Países de Língua Portuguesa - CPLP. 
ULP Law Review | Revista de Direito da ULP

Vol. 13, n. .1

doi: 10.46294/ulplr13n1d4

\section{A Opção pela Intergovernamentalidade}

Parece ser de justificar esta preocupação com a soberania estadual com base em dois fatores:

\section{Os Processos Federativos Contemporâneos e a sua aparente contradição com a}

Soberania Estadual

Uma compreensão adequada da soberania obriga-nos a voltar atrás no tempo, mais concretamente ao momento da queda do Império Romano que levou à dispersão do poder políitico até então unificado.

Após o fim da Época Medieval e a chegada à Idade Moderna, o movimento de centralização do poder político começou a afirmar-se cada vez mais perante o poder feudal, dando origem às monarquias europeias cuja legitimação do poder foi teorizada por autores como Thomas Hobbes ou Jean Bodin.

Na sua obra principal, Os Seis Livros da República, Bodin desenvolveu uma tese de justificação da concentração do poder no monarca através da soberania. Esta última era entendida, de acordo com Hobbes como um poder único e supremo tanto do ponto de vista interno como externo.

Internamente, essa supremacia concretizava-se na capacidade de legislar sem qualquer subordinação a qualquer normatividade superior (desde logo a existência de um direito natural de origem divina). Por sua vez, externamente, o Estado, por ser soberano, "não conhece vinculações de qualquer ordem" ${ }^{2}$ e, neste sentido, cristaliza-se a idade de igualdade soberana entre os Estados.

Segue-se, a corrente iluminista encarnada por vários autores e filósofos, que tanto serviu de sustentação para o despotismo esclarecido (preconizado por Voltaire) que

${ }^{2}$ M.L. Amaral, A Forma Da República. Uma Introdução Ao Estudo Do Direito Constitucional. 2a Edição (Coimbra Editora, Coimbra, 2012), 322. 
ULP Law Review | Revista de Direito da ULP

Vol. 13, n. .1

doi: 10.46294/ulplr13n 1d4

rivalizava o contratualismo associado a vários autores, desde logo Rousseau.

Assim como este último, mas com uma fundamentação distinta, destacaram-se outros autores como John Locke que também se insere nesta corrente contratualista que, mais tarde serviria de impulso para as Revoluções Liberais.

A partir daqui, assistiu-se ao verdadeiro triunfo do direito sobre o poder políitico, iá que “o princípio do Estado de Direito é hoje um princípio que estrutura, pelo menos na Europa, muitas constituiç̄ões nacionais" ${ }^{\prime \prime}$.

Contudo, se os Estados Soberanos "atuavam como os homens no primitivo estado de natureza, sem uma qualquer lei que lhes fosse comum e que pudesse ordenar, de forma paćfíca e durável, a sua convivência rećíproca"4, bem sabemos que esta atuação já não é de todo compatível com 0 mundo contemporâneo.

Mesmo quando, a partir de 1500, o movimento de centralização do poder se estava a afirmar, persistiram algumas partes da Europa Continental que fugiram esta tendência, como se observou na Alemanha e, mais tarde, nos Estados Unidos, que se transmutou de uma Confederaçã̃o de Estados a uma Federação.

0 processo federativo tem vindo a fazer um longo percurso que hoje se tem caraterizado num dinamismo sem precedentes e levanta questoóes ao nível da conciliação destas formas jurílicas de organização do poder políico (materializadas no surgimento de novos sujeitos internacionais) com a preservação da soberania dos Estados.

Porém, não se pense por isso que estamos perante duas realidades necessariamente incompativeis entre si. Mesmo ao nível da União Europeia que constitui, até hoje, 0 exemplo mais paradigmático da supranacionalidade, os Estados continuam a ser sujeitos internacionais.

Por outro lado, também não se verifica uma total subordinaç̧̃o de uma ordem estadual a uma outra de cariz supranacional, sem prejuízz de "formas de atuação jurídica conjunta que se aproximam daquelas que são típicas da federaçãan" ${ }^{\prime 5}$.

\footnotetext{
${ }^{3}$ bid, 323

${ }^{4} \mathrm{lbid}, 322$.

${ }^{5} \mathrm{lbid}, 350$.
} 
ULP Law Review | Revista de Direito da ULP

Vol. 13, n. .9

doi: 10.46294/ulplr13n1d4

$\mathrm{Na}$ verdade, 0 que se assiste é a uma reorganização das funções classicamente atribuídas em exclusividade aos Estados que assenta sobretudo numa ideia de cooperação e não de subordinação. A CPLP, por sua vez, tem na sua génese uma base claramente intergovernamental e, nesse sentido, naturalmente a assunção de competências por parte da mesma terá sempre um âmbito mais restrito. "A ideia era fortalecer as solidariedades horizontais com base na cultura" e na língua comumb', sem embargo de (sem se comprometer a enfâse intergovernamental) não se poder repensar a estratégia de ałuação dos órgãos desta comunidade tendo em vista a potenciação dos seus objetivos.

Enquanto comunidade, conceito de pressupõe conteúdos económicos, políticos, culturais, etc., que geram complementaridades e, consequentemente, formas de solidariedade de vária ordem, a CPLP está longe de ser uma instituição consolidada. Essencialmente, parece faltar ainda à CPLP um projeto que subordine de alguma forma os interesses particulares dos Estados a uma estratégia que os supere?

\section{0 Fenómeno da Globalização e o seu Impacto sobre a Soberania dos Estados}

Na sequência do que se mencionou, na secção anterior, é irrefutável que "no mundo contemporâneo, a condução das relações internacionais já não é mais separável da política interna de cada Estado, como noutras épocas ${ }^{\prime \prime}$. Atualmente, a globalização, traduzida na reorganização dos sistemas produtivos aliada a uma internacionalização do mercado de capitais e nos progressos técnicos e tecnológicos registados, tem vindo a repercutir-se também no direito, desde logo por proporcionar a ascensão de forças centrífugas. A coexistência entre dois conceitos jurídicos cujas lógicas são divergentes. 0 primeiro é 0 conceito de soberania sobre 0 qual se edificou o Estado-Nação (...). 0 segundo é 0 conceito de livre comércio internacional ou de liberalismo, cujo objetivo é a criaçãa de um mercado mundializado pela adoção de um direito puramente económico destinado a

\footnotetext{
${ }^{6}$ A. Moreira, A Crise Do Estado Soberano, № 66 (1993), $27-37$.

${ }^{7}$ A Torres e M. Ferreira, A Comunidade de Países de Língua Oficial Portuguesa № Contexto Da Globalização: Problemas e Perspetivas, (Comunidade dos Países de Língua Portuguesa Cooperação., Coimbra, Almedina, 2001), 25.

${ }^{8} \mathrm{Ibid}, 29$
} 
ULP Law Review | Revista de Direito da ULP

Vol. 13, n. .9

doi: 10.46294/ulplr13n 1d4

ultrapassar as fronteiras dos Estados-Nação?

A este propósito, tome-se como exemplo a tensão entre 0 direito do ambiente e 0 princípio de soberania dos Estados. 0 Estado tem soberania sobre os seus recursos, mas estes têm de explorar os recursos tendo em conta o bem-estar dos povos. Com vista a fazer face a esta dicotomia, assiste-se, tal como já foi anteriormente referido, à ascensão de movimentos de integração regional que congregam esforç̧os para garantir a coes̃ão económica, mas também visam atenuar outras vulnerabilidades, como a primazia da democracia e do direito. Através de uma interpretação articulada dos Estatutos e da Declaração Constitutiva da CPLP, parece ser de entender que a CPLP segue esta linha de pensamento como prinćpio orientador da sua atuação. Porém, o verdadeiro alcance da CPLP em desenvolver intervençōes eficazes neste âmbito nõo atingiv, a meu ver, as aspiraçốes que constam dos seus textos. "Os problemas de sobrevivência da CPLP, sendo 'internos' a cada um dos paises e 'intracomunitários' nas correlaç̧oes que se tecem neste espaço, são igualmente inseparáveis da conjuntura externa" ${ }^{\prime 10}$, mais concretamente do impacto da globalização ao nível do poder políitico, que parece apontar no sentido de reformulaçaco da organização do mesmo e, consequentemente, na redefiniçã̃o das competências orgânicas no seio da CPLP.

\section{A Dimensão Histórica inerente à Opção pela Intergovernamentalidade (A Intergovernamentalidade como Consequência da Descolonizaçõo e posterior Transição para um Estado de Direito Democrático)}

No contexto da CPLP, o fator da Intergovernamentalidade não permite 0 desenvolvimento de políticas verdadeiramente operacionais no quadro desta comunidade. 0 impacto parece ser ainda um pouco limitado em comparação com aquilo que são os objetivos da CPLP, sobretudo no que à promoção dos direitos humanos diz respeito.

\footnotetext{
${ }^{9}$ lbid, 64-65.

${ }^{10} \mathrm{lbid}, 104$
} 
ULP Law Review | Revista de Direito da ULP

Vol. 13, n. .9

doi: 10.46294/ulplr13n1d4

Ainda assim, a vitalidade e o dinamismo da Comunidade refletem-se, também, nos vários mecanismos de colaboração materializados em acordos, convénios e protocolos, não se pretendendo, de todo, desprezar todas as políticas de cooperação realizadas. A descolonização durante as décadas de 70 dos PALOP parecia abrir caminho para a consolidação do Estado de Direito Democrático. É preciso observar que a nova Democracia africana é mais formal que real; é uma democracia limitada, no sentido em que, por adaptação às mudanças da conjuntura internacional, os dirigentes agora ex-marxistas procederam a uma partilha programada do Poder, abrindo um espaço limitado de atuação para a oposiçãa ${ }^{11}$.

Ora, o condicionamento da prosperidade democrática assente nesta ideia de "democracia limitada" que parece proliferar nos países e, para 0 caso em questão, nos PALOP (desde logo Angola e Moçambique onde esta conjuntura é especialmente evidente) compromete uma efetiva realização dos direitos humanos nas suas diversas manifestações. Desde logo porque a supremacia de uma elite governamental determina um acesso dificultado a um conjunto de direitos fundamentais, ainda que legalmente e constitucionalmente os mesmos sejam reconhecidos.

Finalmente, importa referir também a questão da ambivalência cultural que parece caracterizar os países africanos em geral e, em especial, os PALOP. Trata-se de uma especificidade da democracia africana que se caracteriza por uma integração parcial dos africanos nos padrões ocidentais conjugada com uma preservação de traços culturais tracionais que conduzem à formação de uma identidade dualista.

A persistência de tradições ainda profundamente enraizadas nestas comunidades está na base desta ambivalência cultural que muitas vezes, não devendo ser anulada, pode representar alguns entraves na efetivação de direitos fundamentais, tais como o direito à sexualidade e à própria vida.

\footnotetext{
${ }^{11}$ António Sacchetti, Pedro Graça, and Maria Saraiva, A Cooperação Técnico-Militar No Âmbito Da CPLP, (Comunidade Dos Países de Língua Portuguesa, Cooperação, Coimbra: Almedina, 2001), 238.
} 
ULP Law Review | Revista de Direito da ULP

Vol. 13, n. .1

doi: 10.46294/ulplr13n 1d4

\section{Uma Interpretação Articulada dos textos fundadores da CPLP como forma de contornar os limites da Intergovernamentalidade mas sem colocá-la em}

cousa

Como já se disse, não se pode deixar de notar a ênfase que os Estatutos dão a um conjunto de princípios tidos como defensivos da soberania dos Estados-Membros. Das alíneas a); b); c); f) e d) ${ }^{12}$ decorrem obrigações de non facere, mas também de cariz positivo que visam preservar a reciprocidade de tratamento expressa na igualdade soberana dos Estados e no respeito pela integridade territorial e não ingerência nos assuntos internos estaduais.

Contudo, "para além destes princípios, comuns ao velho Modelo de Westfália de Organização da Sociedade Internacional ${ }^{\prime 13}$, os Estatutos também contemplam princípios dinâmicos, tais como aqueles ligados à humanização da vida, autodeterminação dos povos, a democratização e a efetivaçãa dos direitos humanos, finalidades que, de resto, estão em conformidade com a tendência seguida pela Comunidade Internacional. Ora esta ideia de cooperação em vários domínios, sobretudo no desenvolvimento humano, exige um programa de ação dirigido em especial aos agentes das sociedades civis de cada EstadoMembro, já que são estes os principais visados pelas políticas de cooperação ao desenvolvimento e Ajuda Humanitária.

De uma interpretação apurada dos Estatutos, não decorre uma limitação das deliberações dos órgãos da CPLP apenas a um nível intersubjetivo. A eficácia externa não pode deixar de ser tida em conta sobretudo quando, nos termos do artigo $12^{\circ}$ do já citado documento, se constata que o Secretariado não se restringe a uma mera vocação executiva, assumindo-se também como entidade com dimensões político-diplomáticas de representação da CPLP nas plataformas internacionais. Esta é, de facto, uma competência

\footnotetext{
${ }^{12}$ Nos termos do artigo 5\%/ dos Estatutos da (PLP, a CPLP é regida pelos seguintes princípios: a) Igualdade soberana dos Estados membros; b) Não ingerência nos assuntos internos de cada Estado; c) Respeito pela sua identidade nacional; d) Reciprocidade de tratamento.

${ }^{13}$ P. Castro, A CPLP e Os Seus Modelos: Que Comunidade?, (Colóquio de Direito Internacional: Comunidade Dos Países de Língua Portuguesa, Faculdade de Direito da Universidade de Coimbra, 2003), 50.
} 
ULP Law Review | Revista de Direito da ULP

Vol. 13, n. .9

doi: 10.46294/ulplr13n1d4

que operacionaliza aquele que é um dos princípios orientadores da CPLP que se pretende que seja uma plataforma de exteriorização estadual, pois "os Estados-Membros da CPLP sabem que, se aparecerem nestes areópagos internacionais com uma só voz (...) terão mais hipóteses de fazer vingar as suas teses ${ }^{\prime \prime 14}$.

Deste modo, não parecendo impossível que um Estado possa auxiliar diretamente um agente (cultural; económico; social; etc.) de outro Estado-Membro da CPLP, qualquer ação neste domínio deverá ser revestida de particulares cuidados que, desde logo, assegurem 0 respeito pela não ingerência nos assuntos internos desse Estado. Para tal, contudo, os Estados-Membros deveriam desenvolver um verdadeiro programa de ação que, independentemente da área em causa, regulamentasse efetivamente em que modos se poderia estruturar a atuaçãa - quer da CPLP enquanto organização internacional, por um lado, quer dos Estados-Membros, por outro, no desenvolvimento de políiticas públicas nos seus países ou no estabelecimento de planos de auxílio diretos a agentes das sociedade civil de outros Estados-Membros - de modo a não por em causa os princípios que estão na génese da CPLP.

\section{A Perspetiva Prática - Em que se traduziu a atuação da CPLP, enquanto Comunidade, na cooperação para o desenvolvimento e efetivação dos direitos humanos}

\section{A Falta de Políticas Verdadeiramente Operacionais na promoção dos Direitos Humanos}

Sem prejuízo de existirem acordos de cooperação com outras organizações internacionais e entidades da sociedade civil, a CPLP desenvolve essencialmente um enquadramento estratégico comum que serve de base às políticas públicas (nas áreas da saúde, educação, igualdade de género, entre outras temáticas) que depois são executadas pelo Estado-Membro da forma mais conforme possível com esse plano estratégico. Não se

\footnotetext{
${ }^{14} \mathrm{lbid}, 45$.
} 
ULP Law Review | Revista de Direito da ULP

Vol. 13, n. .9

doi: 10.46294/ulplr13n1d4

tratam de políticas verdadeiramente operacionais da parte da CPLP, mas antes de uma concertação de estratégicas comuns que depois são adotadas pelos órgãos internos de cada Estado-Membro.

Poderíamos focar-nos numa análise dos esforços da CPLP em todas as suas áreas de intervenção. Porém, focar-nos-emos no Direito a uma Alimentação Adequada no quadro da CPLP. A opção por esta linha de argumentação deve-se à arrumação sistemática que a segurança alimentar ocupa se a consideramos uma das formas de manifestação do Direito ao Ambiente que constitui condição sine qua non para a concretização dos direitos humanos.

0 que me proponho a analisar mais não é que uma das facetas do Direito ao Ambiente cuja exequibilidade depende essencialmente de três fatores - 0 acesso à informação; a participaçãa na tomada de decisões de impacto ambiental e 0 acesso à justiça.

Analisando, no entanto, estes três pressupostos ainda agora anunciados facilmente constatamos que a interdependência dos direitos humanos condiciona a aplicabilidade do direito ao ambiente à consolidação de um Estado de Direito Democrático onde os Direitos e Liberdades Civis e Políitcos, bem como os Direitos Económicos, Sociais e Culturais estejam garantidos. Já sabemos que os Estados-Membros da CPLP ainda têm um largo caminho a percorrer neste domínio. Contudo, o que se pretende por meio desta exposição é alertar precisamente, através de um exemplo paradigmático, da importância de promover um respeito efetivo e credível dos direitos humanos.

No que diz respeito ao quadro constitucional do Direito à Alimentação, apenas o Brasil apresenta um reconhecimento explícito desse direito na Constituição. "Não obstante, em todos os países verifica-se um reconhecimento implíicito desse direito"15.

Também a nível legal, o Brasil apresenta-se como o único Estado-Membro que possui uma lei específica no campo do Direito à Alimentação. Não podemos esquecer a formulaçã̃o de estratégias institucionais operacionalizadas através dos Conselhos Nacionais de Segurança Alimentar, os quais visam assegurar uma implementação efetiva das políticas

\footnotetext{
${ }^{15}$ Organização das Nações Unidas para a Alimentação e a Agricultura, "Direito à Alimentação e Segurança Alimentar e Nutricional Nos Países da CPLP: Diagnóstico de Base" (Roma: ONU, 2011), 36-37.
} 
ULP Law Review | Revista de Direito da ULP

Vol. 13, n. .9

doi: 10.46294/ulplr13n1d4

públicas desenvolvidas neste âmbito, bem como a criação de redes temáticas constituídas por agentes da sociedade civil ${ }^{16}$ que permitem uma maior articulação dos governos com os organismos ligados à segurança alimentar.

Em todo o caso, a subsistência de limitações humanas, técnicas e organizacionais na maioria dos países tem vindo a dificultar a institucionalidade do Direito à Alimentaçãa. "Na Cimeira Mundial da Alimentação realizada em Roma em novembro de 1996 estabeleceu-se o objetivo de reduzir para metade o número de pessoas desnutridas até 2015. Tal objetivo veio posteriormente a ser incorporado nos ODM aprovados em 2001 pelos países membros da Organização das Nações Unidas" ${ }^{\prime 17}$.

No entanto, "0 relatório de 2011 sobre o progresso relativamente aos Objetivos de Desenvolvimento do Milénio (ODM) na CPLP constata que, na sua grande maioria, estes países registavam atrasos praticamente irrecuperáveis nos quatro anos que restavam até 2015, afirmando serem necessárias decisões de política mais arrojadas e ajudas externas mais robustas ${ }^{\prime 18}$. No que respeita à Segurança Alimentar analisada sob a perspetiva do acesso ao saneamento, com exceção de Portugal e do Brasil, parece evidente que todos os países apresentam grandes condicionalismos. Vejamos um exemplo.

Em Moçambique a revisão da Estratégia de Segurança Alimentar e Nutricional em 2007 através da Resolução n 56/2007 de 16 de outubro destacou-se por já contemplar de forma explííita o direito a uma alimentação adequada. Ainda assim, não se pode deixar de notar que Moçambique não ratificou ainda o Pacto Internacional de Direitos Económicos, Sociais e Culturais, bem como o seu protocolo adicional. A vinculação aos instrumentos de direito internacional poderá gerar um maior sentido de compromisso. Esta realidade é sobretudo evidente quando "quase metade de todas as crianças sofrem de desnutrição crónica em Moçambique, a nona taxa mais elevada de África. 0 Dr. Benedito, Consultor da Secção de Saúde e Nutrição da UNICEF, diz que estas crianças "sofreram de desnutrição crónica em resultado de uma nutrição de má qualidade e de fatores ambientais, tais como

\footnotetext{
${ }^{16}$ Rede Regional da Sociedade Civil para a Segurança Alimentar na CPLP; Rede de Educação, Informação e Cidadania para a Segurança Alimentar na CPLP; Rede CPLP Ambiente e Território; Rede Saúde CPLP; Rede das Plataforma ONG da CPLP.

${ }^{17}$ Organização das Naçōes Unidas para a Alimentação e a Agricultura, "Direito à Alimentação", 6-7.

${ }^{18}$ Idem.
} 
ULP Law Review | Revista de Direito da ULP

Vol. 13, n. .9

doi: 10.46294/ulplr13n1d4

saneamento deficiente" ${ }^{\prime \prime 19}$.

Uma ilustração paradigmática do impacto do mau saneamento sobre outros direitos fundamentais permite-nos concluir que "as doenças provocadas pela água e as doenças associadas ao mau saneamento e higiene constituem um problema significativo em Moçambique. A título de exemplo, em 2015 registaram-se 8.858 casos de cólera, com 65 óbitos em 21 distritos de seis províncias. As crianças de tenra idade estão particularmente em risco" ${ }^{20}$. Acrescente-se ainda que "as mulheres e raparigas são particularmente vulneráveis devido à escassez de serviços de água, saneamento e higiene. Por exemplo, as raparigas perdem tempo de escola, pois têm de ir buscar água, por vezes tomando até duas horas do seu tempo e estão especialmente em risco de agressão sexual se tiverem de ir à casa de banho à noite" ${ }^{21}$. Ainda assim, "a Guiné-Bissau é o país que apresenta maior proporção de pobres (mais de 65\%) e um dos mais atrasados do mundo em termos de desenvolvimento humano. 0 país tem vivido sucessivas crises políticas e institucionais que dificultam a implementação continuada e efetiva das políiticas públicas" ${ }^{\prime 22}$.

Essencialmente, constata-se que os esforços registados são assimétricos quer quanto à agenda estratégica assumida por cada um dos Estados-Membros quer quanto aos instrumentos jurídicos ratificados ou aprovados para fundamentar a ação de políticas públicas.

\section{2. $01^{\circ}$ Encontro de Instituições Nacionais de Direitos Humanos (INDH) dos Estados- membros da Comunidade de Língua Portuguesa e o verdadeiro alcance desta iniciativa}

Tendo como objetivo promover uma maior articulação das estratégias nacionais de cada um dos Estados-Membros da CPLP, realizou-se o I ${ }^{0}$ Encontro de Instituições Nacionais de Direitos Humanos (INDH) dos Estados-membros da Comunidade de Língua Portuguesa em 2013.

\footnotetext{
19 UNICEF, Desfrutando de Um Banho de Chuveiro Pela Primeira Vez, 2016, acedido a 10 de Maio de 2018, em http://www.unicef.org.mz/annualreport2016/pt/wash.html, 14.

${ }^{20}$ Ibidem, 26.

21 Idem.

${ }^{22}$ Organização das Nações Unidas para a Alimentação e a Agricultura, "Direito à Alimentação", 7.
} 
ULP Law Review | Revista de Direito da ULP

Vol. 13, n. .9

doi: 10.46294/ulplr13n1d4

A presente reuniãa visava viabilizar a formalização de uma rede de Instituiçães Nacionais de Direitos Humanos no âmbito da CPLP, bem como a apresentação do Estudo Compreender os Direitos Humanos - Manual de Educação para os Direitos Humanos, coordenado pelo Professor Vital Moreira. Sendo uma iniciativa louvável, que permitirá um maior intercâmbio de experiências e práticas entre os vários países, está ainda comprometida no seu verdadeiro alcance.

De acordo com o ponto primeiro das Competências e Atribuições dos Princípios de Paris uma instituição nacional deverá encarregar-se de velar pela concretização plena dos direitos humanos.

É bom de ver que, se em alguns casos essa figura se materializa numa Comissão nacional dos Direitos Humanos, em outros projeta-se no provedor de Justiça. A questão não está, no entanto, na forma assumida, mas sim na materialidade da mesma.

0 provedor de Justiça Angolano, por exemplo, possui um mandato muito limitado e 0 Estatuto jurídico que lhe é inerente não permite assegurar as necessárias garantias de independência e imparcialidade.

Ainda assim: No relatório que apresentou ao Conselho de Direitos Humanos das Nações Unidas no quadro do mecanismo de Revisão Periódica Universal de 2014, o Governo Angolano manifestou-se disponível para considerar essa solução, mas também afirmou entender que 0 Provedor de Justiça já se conforma plenamente com os Princípios de Paris $^{\prime \prime 23}$.

No entanto, atendendo aos relatórios mais recentes de organismos como a Amnistia Internacional, não se tem vindo a projetar na prática. Fundamentalmente, a criação de uma rede de instituições nacionais de Direitos Humanos exigirá que, antecedentemente, estas estejam sejam uma realidade efetiva nos respetivos países, pois só assim 0 intercâmbio de experiências será verdadeiramente útil e surtirá os efeitos desejados.

\footnotetext{
${ }^{23}$ Observatório Lusófono dos Direitos Humanos da Universidade do Minho, Os Direitos Humanos Em Angola, (Os Direitos Humanos No Mundo Lusófono: 0 Estado da Arte, ed. Jerónimo P., Braga, Escola de Direito da Universidade do Minho, 2015), 25.
} 
ULP Law Review | Revista de Direito da ULP

Vol. 13, n. .9

doi:10.46294/ulplr13n1d4

\section{0 caso particular da Guiné-Equatorial e o seu impacto para a credibilidade da CPLP enquanto instituição potenciadora do Estado de Direito Democrático}

À luz do que já disse, um dos princípios orientadores da CPLP é o primado da paz, da democracia e do Estado de Direito. De uma articulaçãa dos artigos $5^{0}$ e $6^{0}$ reforça- se esta ideia ao estabelecer que a admissão de um novo Estado-Membro implica a aceitação sem reservas dos Estatutos.

Antes da revisão de 20050 antigo artigo $7^{0}$ que versava sobre Medidas Sancionatórias apenas instituía a necessidade de preservar a ordem constituinte, pelo que a eliminação deste preceito e da separação formal dos Estatutos em três capítulos permitiu fortalecer a existência de um Estado de Direito efetivo como critério de adesão à CPLP. Deste modo, "solidificou-se a importância das práticas democráticas, dos direitos humanos e da boa governação enquanto critério de aceitação" ${ }^{\prime 24}$.

Questão diferente, no entanto, remete-nos para o enforcement deste regime. É inegável a existência de força formal e estatutária. Porém, será que materialmente se poderá afirmar que estes critérios são empiricamente verificáveis perante a adesão da Guiné-Equatorial à CPLP? A resposta a esta questão é complexa. Até aos anos 90, a GuinéEquatorial possuía uma economia de subsistência, altamente dependente de ajudas internacionais. Por outro lado, os abusos ao nível dos direitos humanos, corrupção e repressão do regime eram amplamente criticados.

A descoberta da capacidade de extrair petróleo configura um marco importante no país que, por esta via, pretendeu recuperar a sua legitimidade internacional numa dupla perspetiva - em primeiro lugar, transmitindo confiança ao mercado financeiro quanto ao pagamento da dívida internacional; em segundo lugar, do ponto de vista políico, consolidando a estrutura governativa.

De facto, é precisamente neste último âmbito, como forma de pôr fim ao isolamento internacional, que podemos enquadrar a adesão da Guiné-Equatorial na CPLP. “No dia 23 de julho de 2014, a Guiné Equatorial foi aceite como membro de pleno direito da

${ }^{24}$ P. Rigueira, A CPLP e a Guiné-Equatorial: Direitos Humanos Em Questão, (Negócios Estrangeiros 1, 2015), 6. 
ULP Law Review | Revista de Direito da ULP

Vol. 13, n. .1

doi: 10.46294/ulplr13n1d4

Comunidade de Países de Língua Portuguesa (CPLP), naquela que foi a X Cimeira da instituição, em Díli". ${ }^{25}$

Desde a apresentação formal do seu pedido de adesão em 2010 e até julho de 2014, foram realizadas duas Conferências de Chefes de Estado e de Governo.

Na primeira, a ênfase foi dada à criação de um programa de apoio às reformas que 0 país teria de fazer para dar cumprimento às disposições estatutárias da organização, 0 que depois pareceu reforçar-se aquando a segunda conferência em Maputo, em que a a adesão foi afastada perante a vigência da pena de morte no país (Note-se que das questões reafirmadas na XVIII Reunião ordinária do Conselho de Ministros da Comunidade de Países de Língua Portuguesa foram, precisamente, os princípios acolhidos na "Resolução sobre Direitos Humanos e Abolição da Pena de Morte", aprovada pela VIII Reunião Ordinária do Conselho de Ministros (PLP, em julho de 2003), sem prejuízo dos esforços registados quanto ao reconhecimento da Língua Portuguesa através da Promulgação em 2010 de um decreto presidencial que a estabelece como um dos idiomas oficiais do país.

Se parecia que a CPLP estava comprometida a fazer valer os seus princípios orientadores, a verdade é que a Guiné-Equatorial viria a aderir à organização em 2014.

Porém, decorridos três anos desde a sua adesão, o que se verifica é uma total desconformidade com os princípios que estão ou deveriam estar na génese da CPLP.

A pena de morte não foi abolida, mas apenas suspensa por um decreto presidencial, mais concretamente uma moratória materializada pela Resolução 426/2014, de 13 de fevereiro.

Também 0 Decreto 127/2014 de 21 de outubro, que concedeu amnistia a todos os presos políticos" se revela incoerente com a persistência de um regime claramente ditatorial que, mesmo depois do Golpe de Estado, tem subsistido pela mão de ferro de Teodoro Obiang desde 1979.

A violência arbitrária, as constantes repressões aos direitos e liberdades civis e políticas

\footnotetext{
${ }^{25}$ Ana Lúcia Sá, Guiné Equatorial e CPLP: Desafios Ao Futuro Da Lusofonia, (Janus, 2016), 156 , http://hdl.handle.net/10071/10997.
} 
ULP Law Review | Revista de Direito da ULP

Vol. 13, n. .9

doi: 10.46294/ulplr13n1d4

continuam a ser denunciadas pelos relatórios das Organizações Internacionais Governamentais e Não Governamentais que expõem aquilo que é a realidade do país.

É inegável a existência de um desrespeito alarmante pelos princípios orientadores da CPLP que se torna ainda mais grave quando é sabido que a adesão de novos EstadosMembros, assim como a tomada de decisões de todos os órgãos da CPLP e suas instituições (nos termos do artigo $23^{\circ}$ dos Estatutos), está sujeita, nos termos do artigo $6^{0} / 2$ dos Estatutos, ao consenso de todos os membros integrantes desta organização.

Esta vinculatividade meramente formal aos Estatutos denota-se ainda sob outra perspetiva que diz respeito ao estatuto de Observador. Ora, nos termos ponto 1 do artigo $7^{0}$ dos Estatutos, a categoria da Observador Associado, qualidade reconhecida à GuinéEquatorial antes da sua adesão, implica a partilha dos "respetivos princípios orientadores, designadamente no que se refere à promoçã̃o das práticas democráticas, à boa governação e ao respeito dos direitos humanos e prossecução através dos seus programas degoverno objetivos idênticos aos da Organização $0^{26 \prime \prime}$.

Assim sendo, esta questão deveria ter sido debatida muito antes do pedidoformal de adesão por parte da Guiné-Equatorial. A incoerência face à previsão estatutária do artigo $7^{0}$ deveria ter sido o mote para uma avaliação da normatividade dos Estatutos que depois viria a agravar-se ainda mais perante a adesão da Guiné-Equatorial e, consequente, exposição internacional da fragilidade da credibilidade da CPLP enquanto organização internacional fundada na promoção da paz e dos direitos humanos.

\section{Conclusão: Uma análise crítica do percurso da CPLP}

A edificação da subjetividade internacional da CPLP materializa-se através de uma Declaração Constitutiva que expõe os seus objetivos enquanto comunidade institucional que almeja afirmar-se num plano internacional, mas que, essencialmente, manifesta uma

\footnotetext{
${ }^{26} \mathrm{Cf}$. Artigo 7\%/1 dos Estatutos da Comunidade dos Países de Língua Portuguesa.
} 
ULP Law Review | Revista de Direito da ULP

Vol. 13, n. .1

doi: 10.46294/ulplr13n1d4

vontade positiva de vários sujeitos internacionais em constituir uma realidade jurídica dotada de ius tractum e ius legationis.

Porém, não parece satisfatório reduzir a análise da subjetividade internacional a CPLP a estes dois critérios. A crise da soberania dos Estados, motivada pela expansão dos movimentos de integração internacional, faz-nos questionar a admissibilidade de novas dinâmicas de cooperação, até então desconsideradas pelos Estados.

Uma análise do Ato Constitutivo da CPLP permite concluir que a ideia de património cultural comum, desde logo promovida pela criação do Instituto Internacional da Língua Portuguesa, demonstra que a coincidência entre um Estado e uma Nação (no sentido clássico que apela existência de um território delimitado ocupado por um conjunto de pessoas associadas entre si por um vínculo de cidadania que se fundamenta na que existência uma língua e um património comum de costumes e tradições) ocupa uma dimensão reduzida na comunidade internacional.

Com efeito, não só a CPLP se constitui por várias Estados-Membros que, não obstante terem laços comuns, se distinguem entre si, como é inegável a afirmação de novas identidades que obedecem a formas de legitimidade diversas e expõem um aparente desuso dos critérios de caracterização classicamente associados aos sujeitos internacionais.

Esta questão é ainda mais enfatizada quando se constata que, apesar de a CPLP assentar num prinćípio de respeito da soberania dos Estados, tal como, aliás, se refere na própria Declaração Constitutiva, o facto de a comunidade se focar igualmente em valores universais associados à Dignidade de pessoa Humana leva-me a questionar até que ponto esta "incidência universal" não poderá ser 0 mote para a ascensão de uma crise de legitimidade da CPLP, agravada sobretudo pela adesão da Guiné-Equatorial (que se posiciona claramente em contradição com os princípios orientadores desta organização. 